\title{
Metrological solutions for an adapted inspection of parts and tools of a sheet-bulk metal forming process
}

\author{
Steffen Matthias ${ }^{1} \cdot$ Andreas Loderer $^{2} \cdot$ Sergej Koch $^{3} \cdot$ Michael Gröne $^{3} \cdot$ \\ Markus Kästner $^{1} \cdot$ Sven Hübner $^{3} \cdot$ Richard Krimm $^{3} \cdot$ Eduard Reithmeier $^{1}$. \\ Tino Hausotte ${ }^{2} \cdot$ Bernd-Arno Behrens $^{3}$
}

Received: 2 September 2015 / Accepted: 19 November 2015/Published online: 12 December 2015

(C) The Author(s) 2015. This article is published with open access at Springerlink.com

\begin{abstract}
Processes of the new production technology sheet-bulk metal forming allow a fast and efficient nearnet-shape forming of highly complex parts. Thus the need of energy and raw material as well as the production cycle time can be reduced. In order to guarantee these advantages by avoiding scrap and moreover to ensure the parts' geometrical requirements, production-related metrological solutions for an adapted inspection of parts and tools of sheet-bulk forming processes have to be developed. To fulfill the demands of the differing measuring tasks two prototypical measurement solutions are under development: a multi-scale multi-sensor fringe projection system allows for holistic inspections in feature adapted resolutions, whereas a fiberscopic fringe projection system captures the forming tool partly between forming steps. For the purpose of evaluating the metrological solutions' capabilities of capturing the geometry of filigree structures a comparison of both systems is presented in this work. To guarantee realistic results, the performed measuring tasks have to be comparable to the areas of applications both systems were designed for. During the development of the measuring systems the emphasis was put on the inspection of small complex geometries. These are most challenging
\end{abstract}

Steffen Matthias

steffen.matthias@imr.uni-hannover.de

Andreas Loderer

andreas.loderer@qfm.uni-erlangen.de

1 Institute of Measurement and Automatic Control, Nienburger Straße 17, 30167 Hannover, Germany

2 Lehrstuhl Qualitätsmanagement und Fertigungsmesstechnik, Nägelsbachstraße 25, 91052 Erlangen, Germany

3 Institute of Forming Technology and Machines, An der Universität 2, 30823 Garbsen, Germany for fast and reliable optical inspection under productionrelated conditions. By considering measurements of calibrated standards on the one side as well as of measuring tasks resulting out of real sheet-bulk metal forming processes on the other side a realistic comparison is assured. Next to the measuring systems' performances also an approach for combining the measurement data of both metrological solutions is shown. By combining the advantages of both measuring systems, highly detailed information for further interpretations of the forming processes can be provided.

Keywords Sheet-bulk metal forming - In-situ inspection . Fringe projection

\section{Introduction}

Making production processes more efficient by saving resources is one of the key tasks of modern and successful companies in industrial countries. Increasing costs for energy, material and wages require sustainable production technologies, which guarantee a high production value while minimizing the use of resources [23]. The continually increasing number of integrated functions in technical systems together with the demand of a lightweight construction as well as an efficient and sustainable production lead nowadays production technologies to the very edge [3]. In order to develop a new production technology, capable to fulfill all the demands, a new forming technology is researched within the scope of the Transregional Collaborative Research Centre SFB/Transregio 73 [13]. The so called sheet-bulk metal forming (SBMF) combines the advantages of sheet and bulk forming processes with the aim to allow a fast and economical production of 
complex parts with a minimum of material and energy effort [12]. In order to ensure the achieved advantages, measurement systems, adapted on the specific challenges of the sheet-bulk metal forming, are a crucial step in the technology development [7]. By inspecting produced parts, deviations can be detected fast and hence, control variables for readjusting the forming process can be derived. Detecting the forming tool wear in its early stage allows for changing of the tool before defective parts are produced. Thus with both inspection approaches scrap can be avoided and thereby the effectiveness of sheet-bulk metal forming can be improved further [11]. The usage of commercially available measuring systems for production-related measurement of formed parts and forming tools is not possible due to the specific design of sheet-bulk metal forming processes $[16,25]$. The resulting challenges for measuring technologies and the developed metrological solution for adapted inspections are presented in this article. Therefore, the paper identifies metrological tasks of the new class of forming processes in the first section which ends with characteristic challenges. In the second section developed adapted metrological solutions are introduced, which are evaluated by practical experiment in the following fourth section. Before summarizing the findings in the last section, the metrological solutions are compared in the fifth section of the article. Based on existing research on the sheet-bulk metal forming process and corresponding adapted measuring systems, this work presents a collaboration of both fields of research. For the first time corresponding measurements of part and tool of an exemplary sheet-bulk metal forming process are combined and evaluated together.

\section{Metrological tasks in sheet-bulk metal forming processes}

\subsection{Tools and experimental results of a new SBMF process}

In order to produce a solid metal part out of a flat sheet, the new multistage SBMF process has been developed. The target part of this process is a functional component in the form of a gear with internal and external toothing which has been produced by a combination of several forming technologies. Both toothings have an involute gear profile. The complete process sequence of the new SBMF process consists of three forming stages, which include a total of six forming operations. The first forming stage consists of a deep drawing process without blank holder, a cutting process as well as an upsetting process. In the second stage the flange-forming and wall ironing are performed. The third stage of the new SBMF process is used for the calibration of the internal and external toothing [1]. The active tool elements of the individual stages were integrated in a modular tool system [2]. This modular tool system with its active tool elements for the second forming stage is depicted in Fig. 1b.

In comparison to conventional sheet metal forming tools, the tools for the new multistage SBMF process were designed to resist high contact normal stress during the bulk metal forming operations. Unlike the conventional bulk metal forming processes, a semi-finished part for the new SBMF process is made of sheet metal [8]. Furthermore, the tools should enable performing the upstream sheet metal forming operations.

The modular tool system of the new multistage SBMF process enables the combination of sheet and bulk metal forming operations in one forming stage. By appropriate arrangement of the active tool elements of the first forming stage, two- and three-dimensional material flow has been achieved during only one stroke of the hydraulic press. At the beginning of the forming process a semi-finished sheet plate, as shown in Fig. 2, is centred on the die. In the next step, the sheet plate is deep drawn. Simultaneous to the deep drawing step, a hole is cut by the cutting punch in the centre of the cup bottom. The last forming operation of the first stage is upsetting. Thereby the upsetting punch compresses the cup wall and the workpiece material flows upward and laterally in the tooth cavity of the die and the external toothing is formed. The second stage of the new

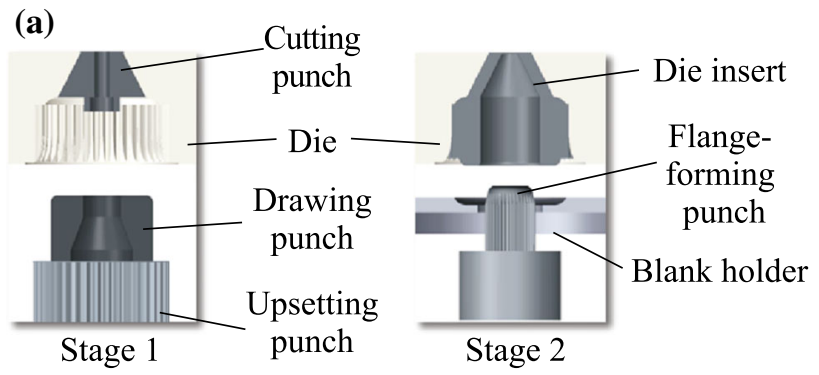

(b)

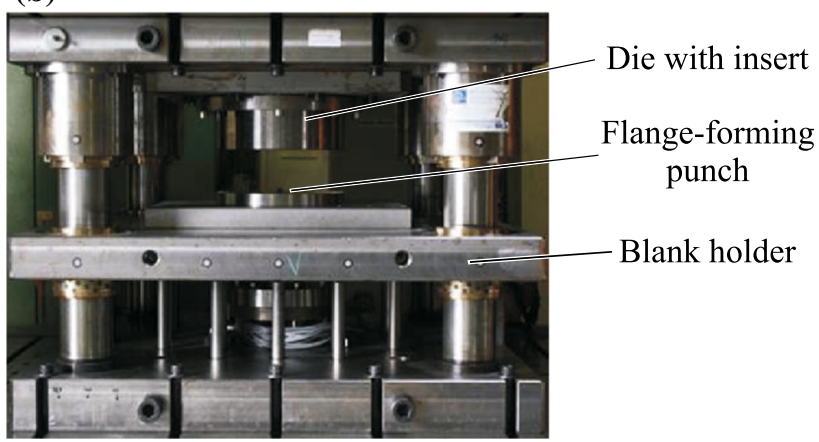

Fig. 1 a Active tool elements of forming stage 1 and 2. b Modular tool system for the new SBMF process with active tool elements for the stage 2 


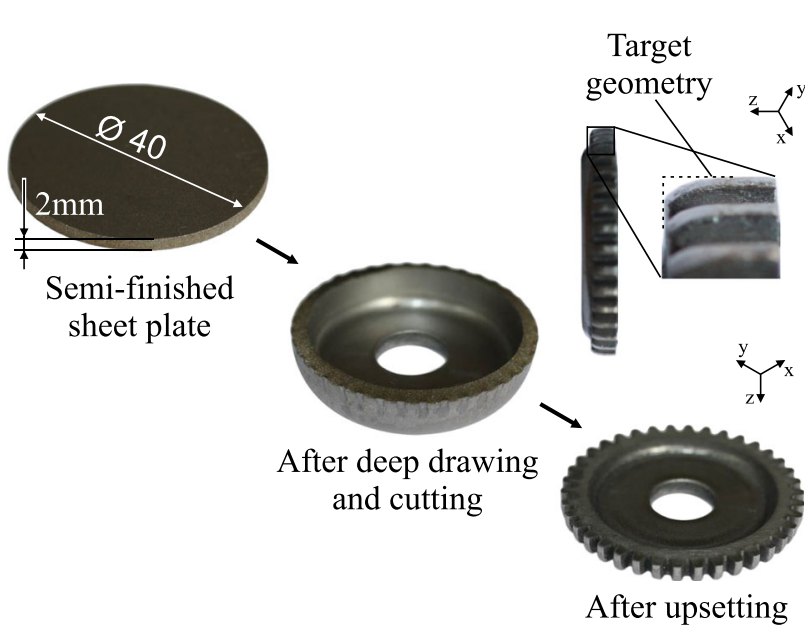

Fig. 2 Experimental results of forming stage 1

SBMF process combines sheet and bulk metal forming operations such as flange-forming and wall ironing. In order to enable these operations, the tool active elements were adjusted, as shown in Fig. 1a. After upsetting, the semi-finished part is placed on the die insert. The blank holder goes up, keeps the part and thus prevents the bending of the external toothing during the flange-forming and wall ironing. In the next step, the flange-forming punch moves through the pre-cut hole and forms the flange in the cup bottom. Due to the fact that the die clearance between the inner diameter of the die insert and the diameter of the flange-forming punch is less than the sheet thickness, wall ironing is realised. During the wall ironing the material flows into the tooth cavities of the flange-forming punch and the internal toothing begins to form. The intermediate experimental results of the first forming stage are shown in Fig. 2. A deep drawing steel DC04 with an initial sheet thickness of $2 \mathrm{~mm}$ was used as workpiece material. A detailed inspection of the upset external toothing has shown that all of the teeth are not completely filled in the external bottom area. The target geometry of the external toothing is depicted in Fig. 2. Possible reasons for this effect could be insufficient forming force at the end of the upsetting operation or imprecise manufacturing of the tooth cavity in the die. In order to detect the cause of the faulty mold filling, the optical geometry measurement of the external toothing and the tooth cavity of the die can be conducted followed by comparisons of the measurement results. None measurement deviations between the tooth cavity of the die and the external toothing of the part indicate an inaccurate manufacturing of the tooth cavity in the die. Furthermore the mold filling of the teeth in the tooth base and tooth flank area can be measured and investigated by a multi-scale multi-sensor measuring system.

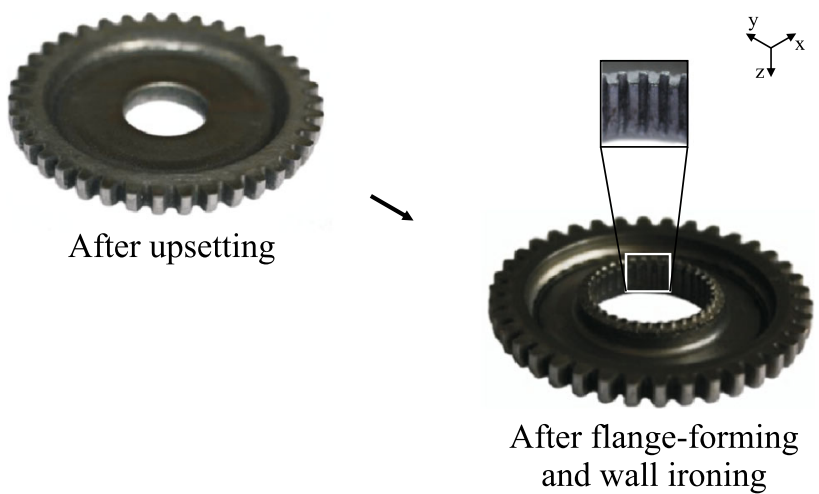

Fig. 3 Experimental results of forming stage 2

The experimental results of stage 2, depicted in Fig. 3, demonstrate that after the combined forming operations, flange-forming and wall ironing, the internal toothing is not completely formed. In this case, the optical geometry measurement of internal toothing and of the tooth cavity on the flange-forming punch provides a statement of actual mold filling.

After the flange forming and wall ironing, the mold filling of the internal toothing cannot be achieved. For this reason, the calibration of the internal toothing will be conducted subsequently in the third forming stage. Furthermore, in order to increase the dimensional accuracy of the internal and external toothing during the complete process sequence, dynamic forces in the form of oscillations will be fed into the force flux of the forming machine by a hydraulic oscillation system [22].

\subsection{Coining gearing elements by means of SBMF in asymmetric parts}

The accurate production of asymmetric parts by means of forming technology is a challenging task due to the existence of horizontal process forces and therewith occurring ram displacement $[4,17,27]$. For investigations of the process-machine interaction while forming asymmetric parts, a tool combining deep drawing and coining gearing elements by means of SBMF was realized [17]. Figure 4a depicts the tool. It is to be utilised with DC04 sheet metal blanks of $100 \mathrm{~mm}$ diameter and a thickness of $3 \mathrm{~mm}$. The tool features three carrier elements at the exterior and gearing elements at the bottom side. Since the gearing elements are rotated by $30^{\circ}$ to the bolster plate, horizontal process forces occur while coining in bottom dead center (BDC). Horizontal process forces lead to ram tilt and horizontal ram displacement as described in [17, 18], and have a negative impact on the part quality as presented in Sect. 4.4. To eliminate the negative influence of the ram tilt, in the context of the research project a new press was 
(a)

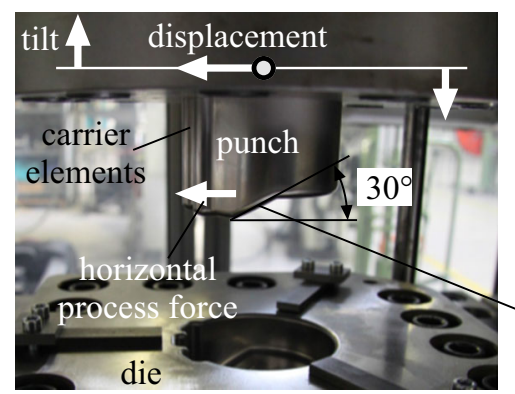

(b)

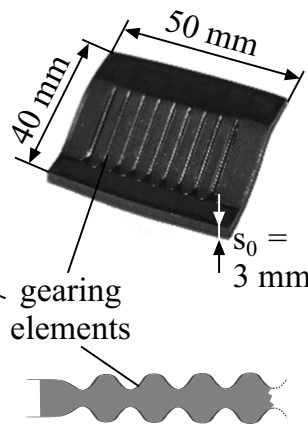

(c)

Fig. 4 a SBMF tool, b finished test part and $\mathbf{c}$ ideal geometry of gearing elements

(a)

(b)

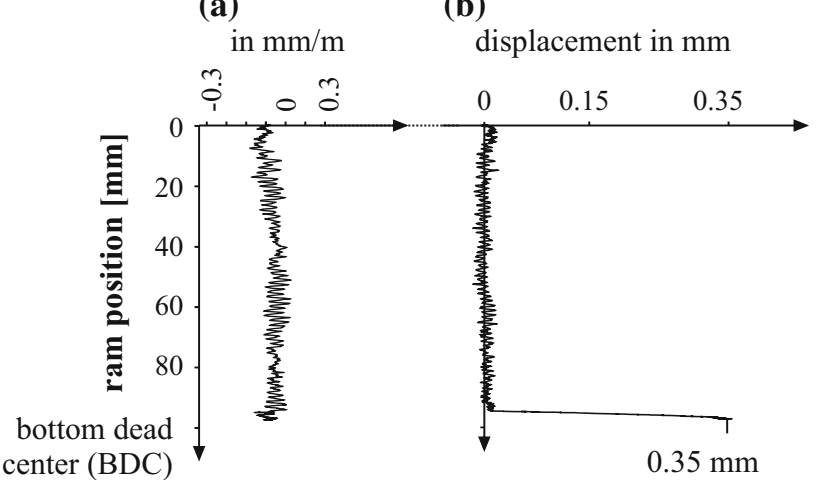

Fig. 5 a Ram tilt (in $\mathrm{mm} / \mathrm{m}$ ) and b horizontal displacement (in $\mathrm{mm}$ )

acquired, which has a ram driven by two mechanically decoupled servomotors [19]. By this technique the press is enabled to control the parallelism of the ram in reference to the bolster plate actively. Anyhow, the horizontal ram displacement can't be avoided by this technique. To probe the press' tilt compensation and measure the remaining horizontal ram displacement due to horizontal loads, a test part as depicted in Fig. $4 \mathrm{~b}$ was produced.

The blank is of $50 \mathrm{~mm} \times 40 \mathrm{~mm} \times 3 \mathrm{~mm}$ size instead of $100 \mathrm{~mm}$ diameter to omit the deep drawing process and just coin the gearing elements. Ram tilt and horizontal displacement were captured by a GOM PONTOS camerasystem while performing a stroke of $100 \mathrm{~mm}$. Figure 5 depicts the results. At BDC the measured forming force is about $750 \mathrm{kN}$. Whereas the ram tilt doesn't rise at the BDC, the horizontal displacement increases up to $0.35 \mathrm{~mm}$ while coining the gearing elements. A ram displacement of such a dimension has a negative impact on the gearing elements. As a result, complete mold filling of the gearing elements cannot be achieved as proved by means of measurements presented in Sect. 4.4. opposing electro- laser sensor to

magnetic force measure displacement

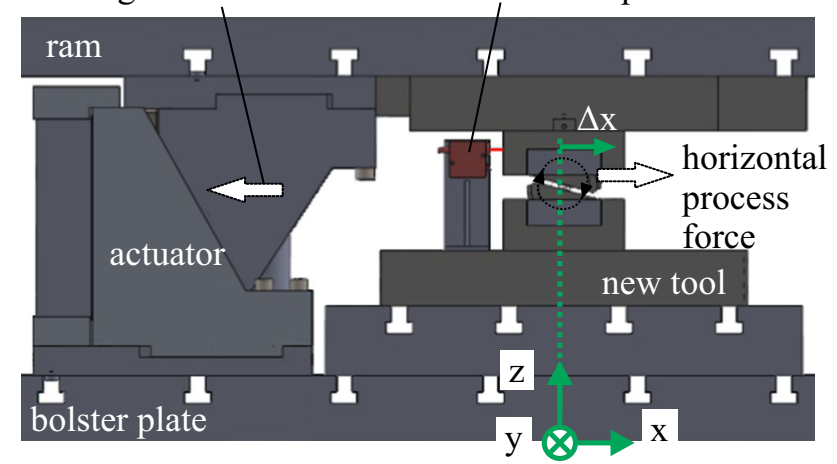

Fig. 6 System to avoid horizontal ram displacement by means of electromagnetic actuators

For further investigations of the impact of varying horizontal loads in processing asymmetric parts, a new tool and a system to avoid horizontal ram displacement are under construction. By means of an electromagnetic system, electromagnetic forces can be applied to the ram of a press (see Fig. 6). The use of an electromagnetic system to avoid horizontal ram displacement by means of opposing electromagnetic forces was presented in [17] first, design and optimisation of the electromagnetic system in [6].

The new tool (illustrated in Fig. 6) has a rotatable punch in order to apply varying horizontal loads and to exploit the potential of the electromagnetic system. With the new tool, the potential of the electromagnetic system and its positive impact on part quality can be probed.

\subsection{Challenges}

The challenges sheet-bulk metal forming imposes for measuring systems and metrological inspection solutions can be divided into three main parts. Firstly, a main challenge is the short inspection cycle time. Sheet-bulk metal forming has the ability to form complex parts in a short cycle time in the range of one second and a proportionally high output rate, which is a great economic advantage. Therefore the inspection of parts and tools needs to be fast, as interruptions of the process impair productivity. For that reason, tactile as well as volume scanning measuring technologies are withdrawn. Both measuring systems of both types are not fast enough for a production-related inspection for a forming technology like SBMF. In contrast, optical measuring technologies are established for fast inspections in production-related environments [20]. Secondly one of the characteristic advantages of sheet-bulk metal forming processes is the possibility of combining features of different scale and size in one part. This can be seen on the demonstrator workpiece, shown in Fig. 7, 


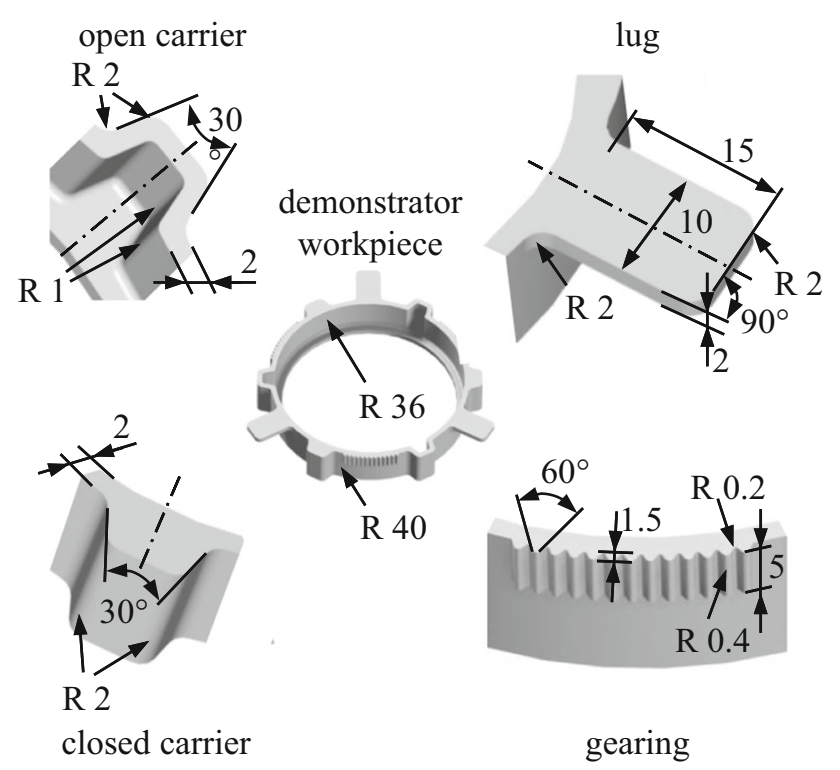

Fig. 7 Demonstrator workpiece features (all radii and distances given in millimeters)

which depicts possible geometries and features of the new forming technology. A holistic and fast inspection of such a complex part with all filigree small but also all larger features or the corresponding forming tool requires adapted metrological solutions. In order to guarantee smooth and even motion of a gear pairing a certain tooth thickness tolerance depending on the diameter of the gearing wheel is to be kept. In case of the demonstrator workpiece with 80 $\mathrm{mm}$ diameter a tooth thickness tolerance of $60 \mu \mathrm{m}$ is recommended (TB21-8 [26]). One crucial aspect is the feature adapted resolution, explained by the "golden rule of metrology" [3]. Georg Berndt set up a rule for selecting appropriate measuring systems in 1968 by considering the systems' measurement uncertainties. The "golden rule" recommends, that the measurement uncertainty should be less than a fifth, better less than a tenth, of a feature's tolerance width. If this minimum requirement could be met, it is assured that the measurement results are accurate enough. When taking the large spread of the feature sizes shown in Fig. 7 into account, a holistic inspection by using a commercially available optical measuring system can be excluded with a required measurement uncertainty of at least $12 \mu \mathrm{m}$ for the smaller elements.

Besides the challenging geometrical side, there are also challenging surface properties. Due to varying local forming forces, the surface roughness and in consequence also the optical properties are inhomogeneous. The resulting optical properties reach from dull and non-direct reflections to shiny and direct reflections. A detailed analysis of these, especially for optical measuring technologies challenging effect, has been already published in [9]. A third main challenging factor is the productionrelated environment and the thereby linked conditions, under which the inspection should take place.

In addition to the aforementioned process specific challenges, the conditions in the forming process need to be considered for the design of the measurement systems. These include specifically variable environment and tool temperatures, vibrations and strong electromagnetic fields, which may interfere with the measurements.

\section{Adapted metrological solutions}

In order to achieve full quality control of the sheet-bulk metal forming process, two different inspection systems based on the fringe projection technique are in development. The first section covers the inspection system for insitu inspection of the tool inside the forming press, while the second section covers the multiscale inspection system for measuring workpieces to allow a better adaption to each measuring object.

\subsection{Fiberscopic fringe projection}

As presented in Sect. 2, continuous tool inspection is required for the sheet-bulk metal forming process. Especially gearing elements are expected to be exposed to increased wear due to the high forming forces. In order to meet this demand as well as to maintain a high manufacturing output, in-situ inspections of the forming tool are desired. Available commercial measurement systems fail to fulfill this requirement due to space limitations in the press. The forming machine used for producing gearings with superimposed oscillations, which is described in Sect. 2.1, has a limited height of about $150 \mathrm{~mm}$ available for the inspection device, while a distance of about $600 \mathrm{~mm}$ needs to be bridged in order to reach the forming tool in the center of the machine. Therefore, a new endoscopic fringe projection system has been developed, which uses flexible image fibers to guide the emitter and detector images for fringe projection profilometry from the base unit to the compact sensor head [15]. The setup of the fiber-endoscopic inspection system, consisting of the measurement device and a positioning device, can be seen in Fig. 8. The positioning device consists of a horizontal and a vertical linear stage and a rotation stage, which is attached to an extended arm. This setup allows to modify the sensor head position inside the press to enable flexible adjustment to different inspection tasks. Axis motion, as well as the measurement procedure, is initiated consecutively by a hardware trigger signal from the host computer. Each axis controller performs the motion towards the tool geometry 


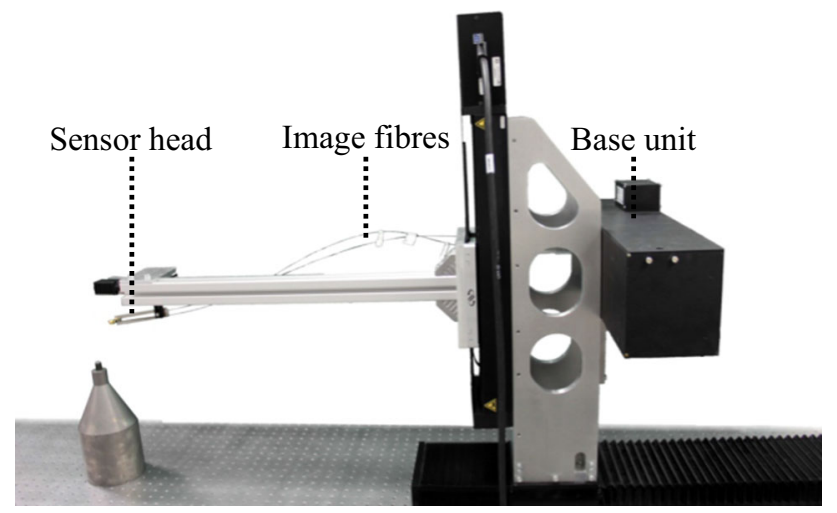

Fig. 8 Fiberscopic fringe projection system for in-situ tool inspection

using a trapezoidal velocity profile with feed-forward PID position control. Compact gradient-index (GRIN) lenses are used in the sensor head, leading to a total height for the extended arm and sensor head of $130 \mathrm{~mm}$. Depending of the task at hand, GRIN lenses with working distances of 10 $\mathrm{mm}$ or $20 \mathrm{~mm}$ can be used, resulting in measuring volumes of about $5 \mathrm{~mm} \times 5 \mathrm{~mm} \times 2.5 \mathrm{~mm}$ with a lateral resolution of about $20 \mu \mathrm{m}$ or $10 \mathrm{~mm} \times 10 \mathrm{~mm} \times 4 \mathrm{~mm}$ with a lateral resolution of about $40 \mu \mathrm{m}$. A laser light source is employed in the pattern generator to enable measurement durations of less than $3 \mathrm{~s}$.

As no electric parts, such as cameras, are positioned inside the machine, the fiberscopic system is resistant against electromagnetic interference. Also the maximum tolerable temperature for the image fibers is $150{ }^{\circ} \mathrm{C}$ compared to approximately $50{ }^{\circ} \mathrm{C}$ for typical industrial cameras.

A complex calibration algorithm has been developed in order to reduce systematic influences due to lens distortions [10]. To enable a robust identification of the model parameters, a large number of calibration points with a distance of less than $125 \mu \mathrm{m}$ in every dimension is captured. The model approach for the camera is based in the pinhole model, while the projector uses polynomial approximations of the phase-depth relation, due to its nonrotationally symmetric optical distortions. As a result of the calibration, metric data can be obtained from the captured phase-maps. Additionally, the transformation from the coordinate systems of the linear and rotationary stages to the sensor coordinate system is estimated. This helps to achieve wide measurement areas in order to cover as much tool surface as possible in single measurements. In combination with the positioning system, the calibration also enables the automatic merging of subsequent measurements to capture larger geometries on the measuring object by using the calibrated transformation matrices. Fine adjustment of the merged point clouds may be calculated with the iterative closest point algorithm.

\subsection{Multi-sensor fringe projection}

The demands of a holistic inspection of formed parts can be met best by a multi-scale multi-sensor approach. Thereby each feature is measured by a sensor with a feature adapted measurement range, resolution and uncertainty. The resulting several datasets are combined together, which leads to a holistic dataset of different scales [21]. The inspection principle is shown in Fig. 9 by using an exemplary gearing. The highly reflective areas of the gearing cannot be measured properly by using only the overview sensor. Gaps and lack of measuring points are the result. In addition to this, the accuracy of the sensor would not be good enough to measure all parameters of the gearing even if all areas could be detected. Therefore the marked area of the measuring object is measured and detailed by both detail sensors. For a comprehensible explanation, the detailing is shown only on one part of the gearing. The

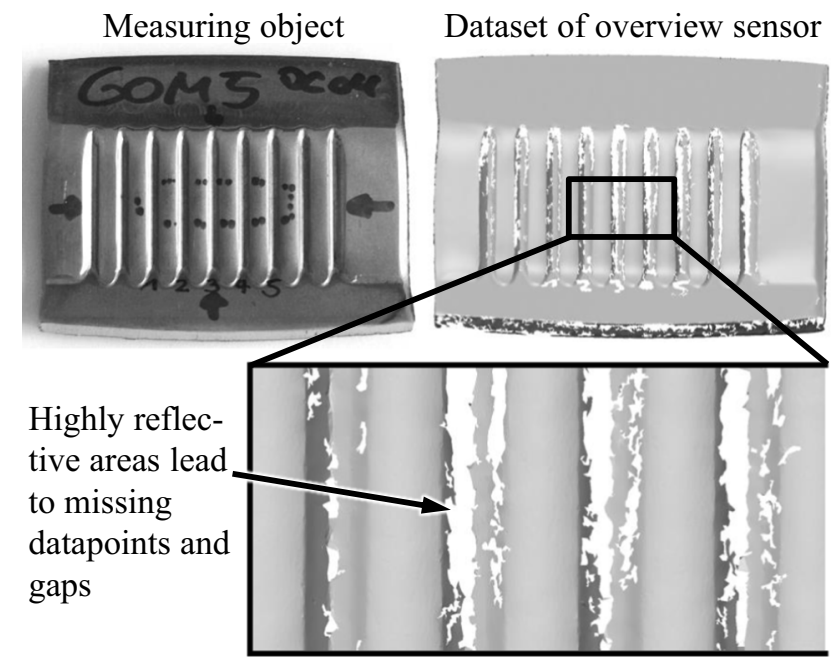

Detailed multi-scale multi-sensor dataset

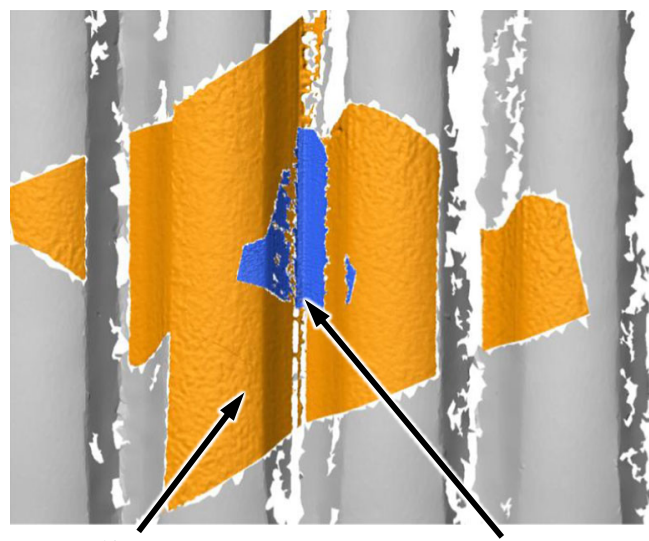

Detail sensor $1 \quad$ Detail sensor 2

Fig. 9 Multi-scale-principle 
tooth tips are measured with the detail sensor 1 whereas the geometrical properties of the smaller tooth root require the more accurate detail sensor 2. By combining all datasets, a holistic and feature adapted multi-scale multi-sensor dataset emerges.

For the realization of the multi-scale multi-sensor approach a prototypical measuring system, shown in Fig. 10 was worked out, consisting of three different types of commercially available fringe projection sensors. Each type has a differing measurement range and thus also

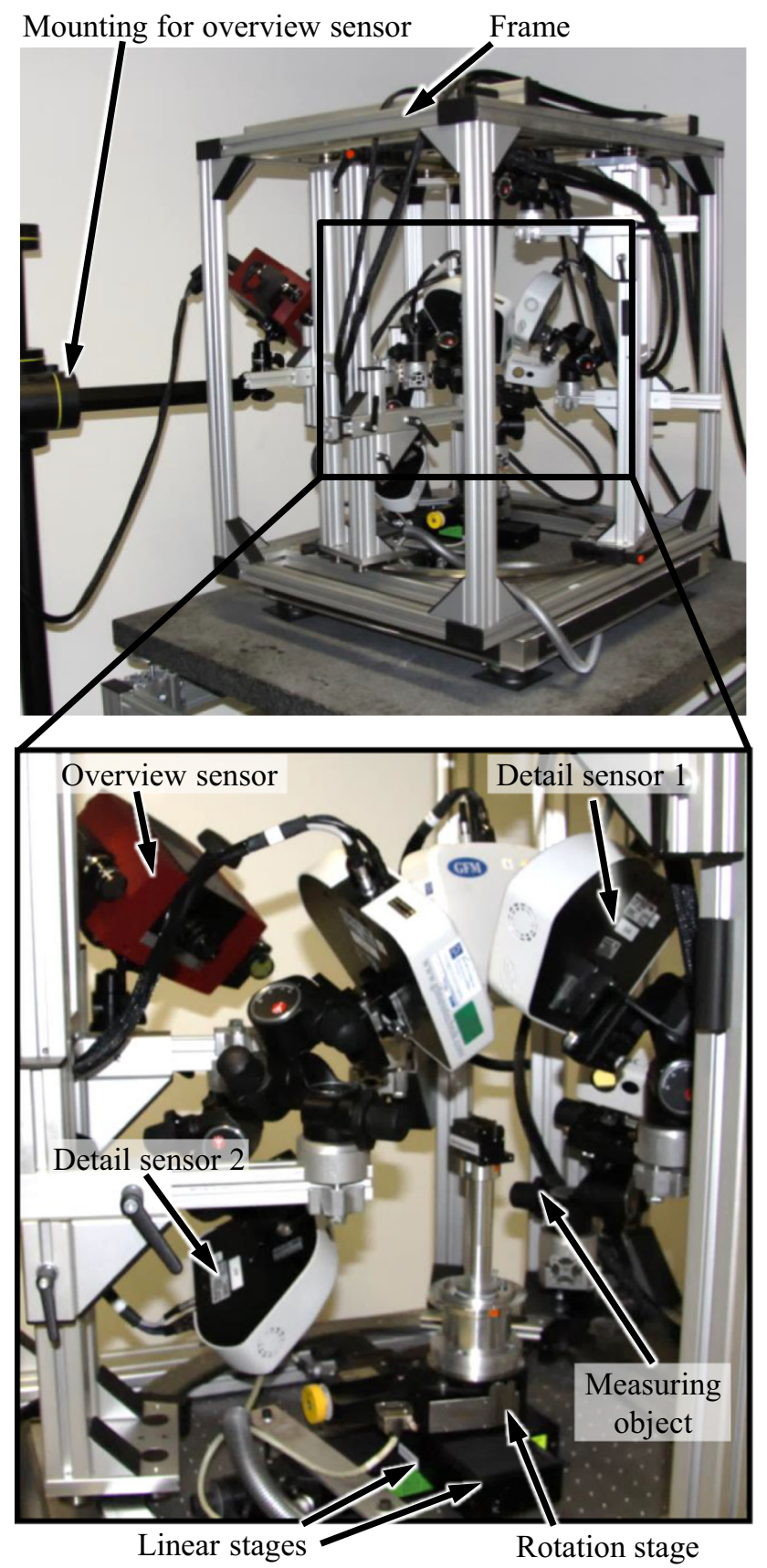

Fig. 10 Multi-scale-system different resolutions. A GOM ATOS Compact Scan 2M fringe projection sensor (measurement range: $115 \mathrm{~mm}$ x 88 $\mathrm{mm} \times 92 \mathrm{~mm}$; mean point spacing: $21 \mu \mathrm{m}$ ) is used as an overview sensor. This type of sensor has a measurement range of approximately the size of the measuring objects and can provide a rough data framework of the measuring object as well as measurements of large features at once. Where the resolution of the overview sensor is not accurate enough, the dataset can be detailed by using two different additional types of fringe projection sensors. Each sensor captures only one feature or only a part of a feature, but in a resolution, which is adapted to the feature's size and tolerance. In the prototypical measuring system, according to the measuring task and setup, up to eight GFM MicroCAD $1.0 \mu \mathrm{m}$ (measurement range: $13 \mathrm{~mm}$ x $10 \mathrm{~mm}$ x $3 \mathrm{~mm}$; lateral resolution: $17 \mu \mathrm{m}$; vertical resolution: $1.0 \mu \mathrm{m})$ as well as up to four GFM MicroCAD $0.3 \mu \mathrm{m}$ (measurement range: $4 \mathrm{~mm} \times 3 \mathrm{~mm} \times 1 \mathrm{~mm}$; lateral resolution: $2.5 \mu \mathrm{m}$; vertical resolution: $0.3 \mu \mathrm{m}$ ) can be used as detail sensors. For the exemplary measuring setup shown in Fig. 10 only three GFM MicroCAD $1.0 \mu \mathrm{m}$ and two GFM MicroCAD $0.3 \mu \mathrm{m}$ were installed. A calibration procedure, developed for the multi-scale multi-sensor measuring systems, allows determination of the necessary transformation in order to combine each dataset.

In order to provide a reliable setup in a productionrelated environment, the detail sensors are installed in a robust and damped frame, which allows an arrangement around the part. Two linear stages move the part in $\mathrm{x}$ - and $y$-direction, whereas a rotation stage enables a rotation around the z-direction. Due to the required measuring distance, the overview sensor is not mounted fix in the frame. All sensors are exchangeable and the setup is expandable.

\section{Inspection of sheet-bulk metal forming tools and workpieces}

\subsection{Assessment of the measuring performance with a calibrated standard}

In order to evaluate the performance of the different measurement systems in terms of measurement accuracy, features on a calibrated micro-contour standard by Alicona, which has been developed in cooperation with the PTB [14], are measured. The features, which can be seen in

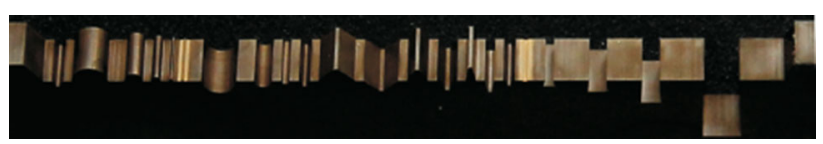

Fig. 11 Features on the micro-contour standard 
Fig. 11, are calibrated with an uncertainty of $0.7 \mu \mathrm{m}$. The evaluation allows to give a quantitative assessment of the capability of the sensors to detect slow growing wear on the tool or deviations on the product. As the sensors to be evaluated measure in different scales, the $1 \mathrm{~mm}$ radius and $1 \mathrm{~mm}$ step features have been selected as the largest elements on the standard. This ensures capturing enough data points on each element to achieve meaningful results. In addition, each measurement has been repeated for 25 times to ensure the repeatability of the measurements. It needs to be noted, that no repositioning of the standard has been performed in between measurements. As the measuring performance of fringe projection systems is dependent on the measuring angle [24], the sensors have been positioned approximately perpendicular to the standard's surface for optimal results.

The evaluation of the features' sizes was done with Polyworks IMInspect V14 (Duwe-3d AG, Lindau, Germany). In the first evaluation step, for evaluating the actual radii sizes, only measurement data points of the cylinder's surface were used. Therefore all outer data points were cut out. In the remaining points of each dataset a cylinder feature was fitted by using the IMInspects best-fit-algorithm, which contains also a filtering step by omitting five percent of the data points with the largest deviations to the calculated cylinder feature. This type of evaluation allows an estimation of the systematic errors in the measurement. In the second evaluation step, for determining of the measuring points' standard deviations, a cylinder of the calibrated size of $1.0015 \mathrm{~mm}$ was fitted into the data points. The approach for the evaluation of step heights was similar. In order to gather only vertical distances between the step height's base and the step area itself, the fitted plains of base and step had to be parallel. Again the IMInspect's best-fit-algorithm and the related filtering of five percent of the data points were used. For determining the standard deviation only data points of the step area were considered. The standard deviation allows to assess the measurement noise present in the datasets.

The results of the feature estimation are shown in Table 1 for the radius feature and in Table 2 for the step feature. It can be seen that ATOS Compact Scan 2M sensor, which is used for large scale geometry acquisition, has the lowest accuracy for both features with a deviation above $100 \mu \mathrm{m}$ for the radius element. Both MicroCAD sensors exhibit a low systematic error of less than $5 \mu \mathrm{m}$ for the radius and step feature. For the estimation of the radius and step feature parameters, the endoscopic system achieves results comparable to the MicroCAD systems, however the standard deviation is slightly higher.

As the ATOS Scan 2M system is used only as an overview sensor, the point count is relatively low for the evaluated features. This leads to high deviations in the results. However, these deviations are not significant, because the multi-scale system is capable of combining the large-scale measurement with the higher-resolution measurements of the MicroCAD sensors. The results of the endoscopic fringe projection system prove, that the calibration algorithm is capable of describing lens distortion and fiber grid effects accurately. Compared to the MicroCAD systems, the measurement noise in the point clouds is higher, which is due to the speckle arising from the laser illumination used.

While the geometry of the features on the standard are not identical to the geometry of the gearing elements on the micro-contour standard, the systematic and stochastic deviations estimated for the standards features are lower than the uncertainty requirement of $12 \mu \mathrm{m}$ derived from the

Table 1 Evaluation of the radius feature (mean over 25 measurements)

\begin{tabular}{lccrr}
\hline & MicroCAD 1.0 & MicroCAD 0.3 & ATOS Compact Scan 2M & Fiberscopic system \\
\hline Point count & 4,819 & 28,275 & 368 & 21,704 \\
Standard deviation (point-reference) $(\mu \mathrm{m})$ & 3 & 2 & 29 & 6 \\
Mean deviation (fitted radius) $(\mu \mathrm{m})$ & 5 & 3 & -101 & 5 \\
Not measurable & 0 & 0 & 0 & 0 \\
\hline
\end{tabular}

Table 2 Evaluation of the step feature (mean over 25 measurements)

\begin{tabular}{|c|c|c|c|c|}
\hline & MicroCAD 1.0 & MicroCAD 0.3 & ATOS Compact Scan $2 \mathrm{M}$ & Fiberscopic system \\
\hline Point count & 2,221 & N/A & 152 & 11,708 \\
\hline Standard deviation (point-reference) $(\mu \mathrm{m})$ & 3 & N/A & 12 & 10 \\
\hline Mean deviation (fitted step) $(\mu \mathrm{m})$ & 2 & N/A & -6 & 2 \\
\hline Not measurable & 0 & 25 & 3 & 0 \\
\hline
\end{tabular}


tolerances described in Sect. 2.3. Thus, it is expected that the adapted inspection systems are capable of measuring the gearing elements with the required uncertainty.

\subsection{Inspection of an exemplary workpiece}

For measuring the gear, the overview sensor was used to detect the rough shape. By adjusting the measuring ranges of the detail sensors on the teeth and the upper side of the gear, a detailing of the dataset was possible. Moreover gaps and lack of measuring points in the teeth area as well as measuring error due to optical effects in the area of the circular radius on the upper side could be removed by the more accurate detail sensors. The resulting multi-scale multi-sensor dataset was used for a comparison with the ideal forming tool in order to detect form filling deviations.

Section 2.1 describes the manufactured parts of the new multistage SBMF process. The detailed inspection of these

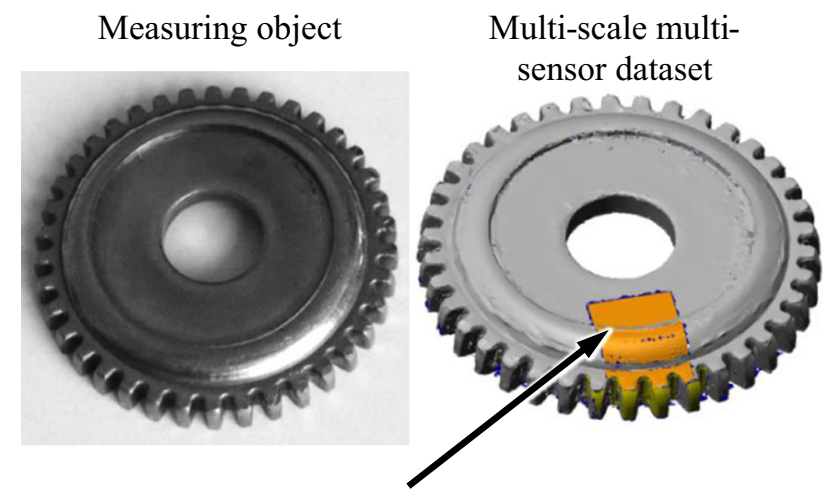

Datasets of detail sensors for detection ofmould filling

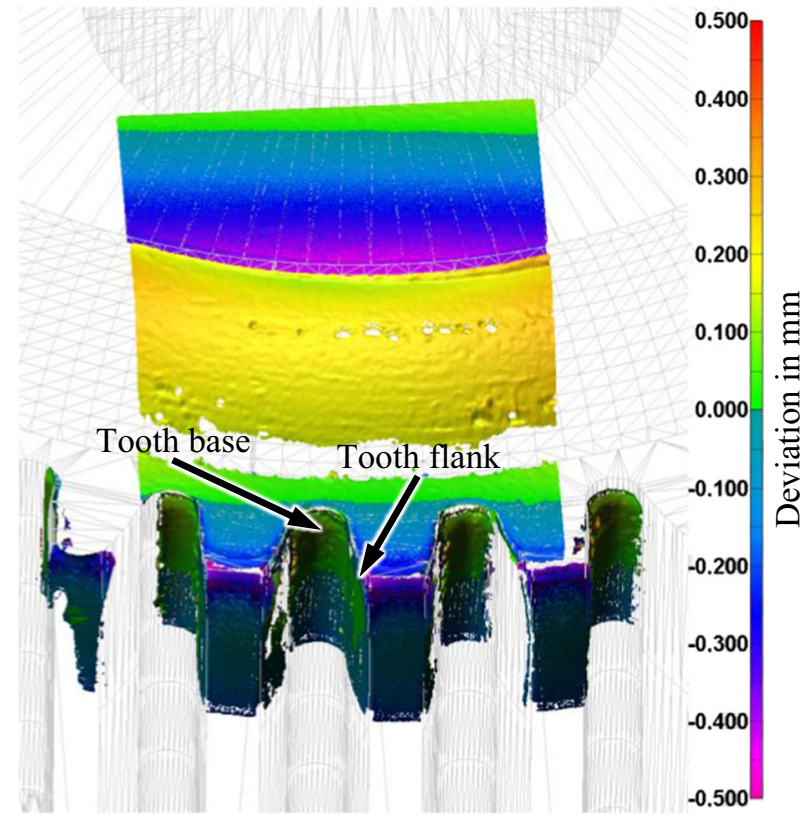

Fig. 12 Measurement of the workpiece

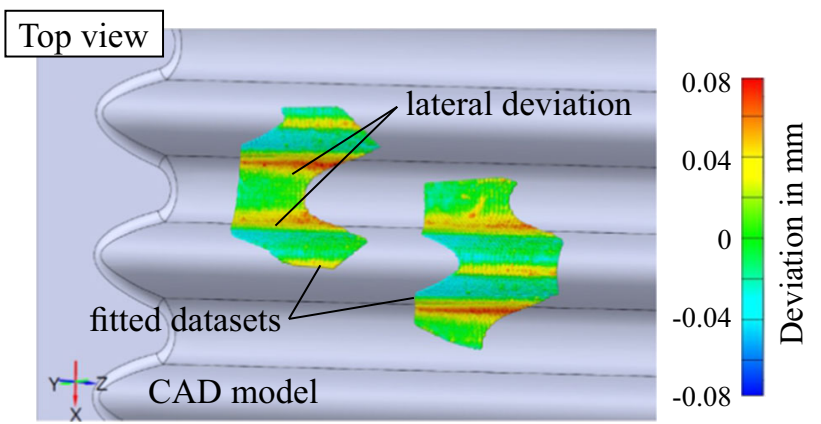

Fig. 13 Deviation analysis of gearing elements on the tool

parts has demonstrated that the external toothing is not completely filled. In order to investigate the geometry of internal toothing more precisely, the multi-scale multisensor measuring system was used. Figure 12 shows the measurement area on the part and the comparison between the measurement results and the 3-D-CAD model of the die. The represented geometrical deviation of the target geometry is partial $0.5 \mathrm{~mm}$. Such deviations indicate an inaccurate manufacturing of the tooth cavity in the die. Furthermore, the measurement results illustrate a good mold filling in the high stressed areas such as tooth bases and tooth flank of the external toothing.

\subsection{Inspection of an exemplary tool}

Measurements of the tool's gearing elements (see Fig. 4) were made by means of the fiberscopic fringe projection system (see Sect. 3.1). The tool is made of hardened 1.2379 steel, which has a highly reflecting surface. Despite this,
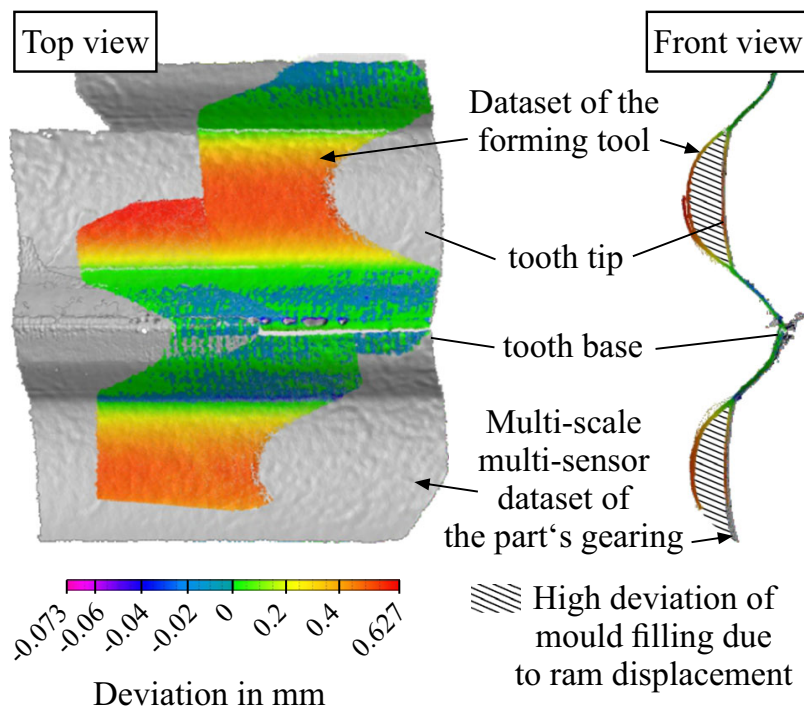

Fig. 14 Deviation analysis of formed gearing elements 
valid datasets could be obtained without the need of matting materials. Figure 13 depicts two single measurements of $4 \mathrm{~mm} \mathrm{x} 4 \mathrm{~mm}$ size fitted to the CAD model. There is a maximum lateral deviation between model and measurement of $0.08 \mathrm{~mm}$ recognisable. The deviation might be caused by manufacturing defects of the tool or wear in form of lateral build-up by welding due to high loads on the tool while coining the gearing elements.

\subsection{Comparison of tool and part impacted by horizontal ram displacement}

The amount of mold filling is a significant indicator for the part quality. To determine the mold filling measurements of the tool and the part depicted in Fig. 4 were conducted. The part's gearing elements were measured by means of the multi-sensor fringe projection system (see Fig. 9). The tool was measured by the fiberscopic fringe projection system (see Sect. 4.3). The datasets of both systems were fitted to each other for an exemplary dimensional check of a part. Figure 14 depicts the fitted datasets. The tooth base was used as a reference for fitting, since the contact of tool and sheet metal is the highest while coining the gearing elements.

Between the tooth tips of the part and the tool a difference of about $0.6 \mathrm{~mm}$ can be stated. The insufficient mold filling is a result of the horizontal ram displacement while coining the gearing elements [17]. By realizing the electromagnetic system as described in Sect. 2.2, the amount of mold filling will be raised in future.

\section{Conclusion and outlook}

In this article the new sheet-bulk forming technology was introduced and its capabilities for the production of highly complex parts demonstrated. Its challenges, especially for metrological inspections of parts and tools, were presented. Based on these challenges, two adapted measuring systems, both using the principle of fringe projection technology, were developed. Whereas the fiberscopic fringe projection system is designed for fast measurements of small geometries on forming tools in homogeneous precision, the multi-scale multi-sensor fringe projection system is optimized for gathering a holistic dataset of formed parts in a resolution adapted to certain features. By measuring a radius and step height feature of a calibrated micro-contour standard the systems' performances could be evaluated and the precision as well as spreads of data points could be estimated roughly. The qualification of both measuring systems for their specific measuring tasks could be proven by performing different measurements of parts and tool of the current state of SBMF-processes' developments.
The next development step of the measurement solutions is the integration in a running process chain. Then the in-situ measurement of the forming tool and a productionrelated measurement of parts can be further optimized and a time optimized evaluation of the deviations of the processes can be researched. For this next step a process chain has to be defined and established, which could for example be a combination of the individual forming steps demonstrated in this work. Furthermore a more detailed comparison of both measuring systems could be provided by determining their measurement uncertainties considering the GUM-standard [5].

Acknowledgments The authors are grateful to the German Research Foundation (DFG) for supporting the investigations in the research project "Manufacturing of complex functional components with variants by using a new metal forming process Sheet-Bulk metal forming" (SFB/TR 73, online: https://www.tr-73.de).

Open Access This article is distributed under the terms of the Creative Commons Attribution 4.0 International License (http://crea tivecommons.org/licenses/by/4.0/), which permits unrestricted use, distribution, and reproduction in any medium, provided you give appropriate credit to the original author(s) and the source, provide a link to the Creative Commons license, and indicate if changes were made.

\section{References}

1. Behrens BA, Bouguecha A, Vucetic M, Hübner S, Rosenbusch D, Koch S (2015) Numerical and experimental investigations of multistage sheet-bulk metal forming process with compound press tools. Key Eng Mater 24(4):045002

2. Behrens BA, Hübner S, Vucetic M (2013) Influence of superimposing of oscillation on sheet-bulk metal forming. Key Eng Mater 554:1484-1489

3. Berndt G, Hultzsch E, Weinhold H (1968) Funktionstoleranz und Messunsicherheit. Wissenschaftliche Zeitschrift der Technischen Universität Dresden 17(2):465-471

4. Brecher C, Esser M, Witt S (2009) Interaction of manufacturing process and machine tool. CIRP Ann Manuf Technol 58(2):588-607

5. des Poids et Mesures BI (1995) Électrotechnique internationale, C., internationale de normalisation, O.: Guide to the expression of uncertainty in measurement. International Organization for Standardization

6. Gröne M, Salfeld V, Krimm R (2014) Design of an electromagnetic system to avoid horizontal ram displacement. Adv Mater Res 1018:237-244

7. Kunzmann H, Pfeifer T, Schmitt R, Schwenke H, Weckenmann A (2005) Productive metrology - adding value to manufacture. CIRP Ann Manuf Technol 54(2):155-168

8. Lange K, Kammerer M, Pöhlandt K, Schöck J (2008) Fließpressen. Fließpressen: Wirtschaftliche Fertigung metallischer Präzisionswerkstücke 1

9. Loderer A, Timmermann M, Matthias S, Kästner M, Schneider T, Hausotte T, Reithmeier E (2015) Measuring systems for sheetbulk metal forming. Key Eng Mater 639:291-298

10. Matthias S, Kästner M, Reithmeier E (2015) Evaluation of system models for an endoscopic fringe projection system. Measurement 73:239-246 
11. Merklein M, Allwood JM, Behrens BA, Brosius A, Hagenah H, Kuzman K, Ki M, Tekkaya AE, Weckenmann A (2012) Bulk forming of sheet metal. Ann CIRP 61:725-745

12. Merklein M, Gröbel D, Löffler M, Schneider T, Hildenbrand $P$ (2015) Sheet-bulk metal forming of functional components from sheet metals. In: Qin Y, Dean TA, Lin J, Yuan SJ, Vollertsen F (eds) Proceedings of the 4th international conference on new forming technology, pp 01,001 1-12. MATEC Web of conferences

13. Merklein M, Schneider T, Gröbel D, Nürnberger F (2014) Blechmassivumformung vom halbzeug zumfunktionsbauteil. In: Behrens BA (eds) 21. Umformtechnisches Kolloquium Hannover, Industrie und Wissenschaft - Gemeinsam die Zukunft gestalten, pp 265-280

14. Neuschaefer-Rube U, Neugebauer M, Dziomba T, Danzebrink HU, Koenders L, Bosse H (2011) Neuere Entwicklungen von Normalen für die 3D-Mikro-und Nanometrologie. Technisches Messen Plattform für Methoden, Systeme und Anwendungen der Messtechnik 78(3):118-126

15. Ohrt C (2013) Development of a measuring endoscope for the inline quality control of filigree form elements in forming production lines. Ph.D. thesis, Leibniz Universität, Hannover

16. Ohrt C, Hartmann W, Kästner M, Weckenmann A, Hausotte T, Reithmeier E (2012) Holistic measurement in the sheet-bulk metal forming process with fringe projection. Key Eng Mater 504:1005-1010

17. Salfeld V, Krimm R, Hübner S, Matthias T, Vucetic M (2013) Sheet-bulk metal forming of symmetric and asymmetric parts. Adv Mater Res 769:229-236

18. Schrobbach H (1995) Kompensation der Stößelkippung an mechanischen Zweipunktpressen unter der Berücksichtigung des Horizontalversatzes im Werkzeugsystem. Ph.D. thesis, TU Chemnitz-Zwickau
19. Schuler Pressen GmbH: Twinservo technology-advanced servo presses. www.schulergroup.com/major/download_center/broschue ren_automotive/download_automotive/automotive_broschuere_ twin_servo_technologie_e.pdf (2015). Accessed: 2015-08-31

20. Schwenke H, Neuschaefer-Rube U, Pfeifer T, Kunzmann $H$ (2002) Optical methods for dimensional metrology in production engineering. CIRP Ann Manuf Technol 51(2):685-699

21. Shaw L, Ettl S, Mehari F, Weckenmann A, Husler G (2013) Automatic registration method for multisensor datasets adopted for dimensional measurements on cutting tools. Meas Sci Technol 24(4):045002

22. Stankowic P (1958) Static-dynamic forging principals and some characteristics. Metal Treat Drop Forg 159(25):489-494

23. Steinhilper R, Kruse A, Drews T (2013) Ecological analysis of manufacturing systems focusing on the identification of varietyinduced non value adding emission. In: Seliger G (ed) Proceedings of the 11th global conference on sustainable manufacturing-innovative solutions. Universitätsverlag der TU Berlin, Berlin, pp 66-71

24. Weckenmann A, Hartmann W, Weickmann J (2008) Multicomponent fringe projection sensors: assistance system for short and robust inspection processes. In: Proceedings of the 2008 NCSL international workshop and symposium (NCSL, 2008), pp 43-49

25. Weickmann J, Weckenmann A, Brenner P-F (2010) Automatic, task-sensitive and simulation-based optimization of fringe projection measurements. Key Eng Mater 437:439-443

26. Wittel H, Muhs D, Jannasch D, Voiek J (2009) Tabellenbuch. Vieweg+Teubner doi:10.1007/978-3-8348-9998-9_24

27. Zhang HG, Dean TA (1995) Computer modelling of tool loads and press/tool deflections in multistage forging. Int J Mach Tool Manuf 35(1):61-69 